\title{
МАТЕМАТИЧНЕ МОДЕЛЮВАННЯ ВЗАЄМОВПЛИВУ ДИНАМІЧНИХ ХАРАКТЕРИСТИК СИПКОЇ СИРОВИНИ У ПРОЦЕСІ ВІБРАЦІЙНОЇ СЕПАРАЦІЇ
}

\begin{abstract}
Здійснено огляд останніх досліджень у сфері вібраційної сепарації сипкої сировини. Виявлено, що на продуктивність процесу сепарації впливають не тільки конструкційні характеристики вібраційного сепаратора, зокрема довжина, кут нахилу та ємність робочого корпуса, але й динамічні процеси, які відбуваються у сипкій сировині у процесі сепарації. Ефективність процесу сепарації істотно залежить від взаємовпливу швидкості завантаження, руху сипкої сировини вздовж сита вібраційного сепаратора та іiї амплітудо-частотних характеристик. На підставі здійсненого огляду встановлено актуальність подальшого дослідження цих параметрів. Використовуючи методи нелінійної механіки, побудовано математичну модель руху шару сипкої сировини по ситу вібраційного сепаратора. При цьому шар сировини моделюється пружною балкою, яка контактує пружно, жорстко або як шарнірно закріплена зі стінками робочого контейнера. Отримано графічні залежності впливу швидкості руху шару сипкої сировини на амплітуду та частоту ії коливань. Отримані математична модель та графічні залежності показують, що значне збільшення швидкості руху сипкої сировини вздовж сита призводить до спадання амплітуди та незначного зростання частоти коливань шару завантаженої сировини. Аналогічно і сталі складові швидкостей впливають на збільшення власної частоти коливань сипкої сировини, що відповідно погіршує ефективність проходження частинок крізь сито сепаратора. Невеликі швидкості руху шару сипкої сировини призводять до зростання амплітуди коливання та зменшення частоти коливання, що сприяє підвищенню прохідності частинок сировини та збільшенню продуктивності процесу сепарації. Отримані дослідження дають змогу покращити ефективність процесу сепарування, регулювати процеси, які відбуваються у сипкій сировині та підвищити швидкість ії проходження крізь отвори сита. Побудована математична модель може слугувати основою для подальших досліджень зміни фізико-механічних характеристик сипкої сировини на ії динамічні показники в процесі вібраційної сепарації.
\end{abstract}

Ключові слова: динамічні характеристики; амплітуда; частота; сипка сировина; математична модель.

\section{Вступ}

Оброблення та переробляння сировини є незмінним процесом будь-якого виробничого циклу. До проміжних етапів оброблення сипкої сировини належать сепарація, змішування, транспортування, дозування, ущільнення та інші. Використання вібраційного обладнання та, безпосередньо, вплив вібрації на оброблювану сировину сприяє покращенню якості вихідної продукції, зокрема, завдяки постійному струшуванню відбувається розрихлення частинок сировини та досягається високий ступінь їх поділу за фізико-механічними властивостями. На ефективність проходження частинок сипкої сировини крізь отвори сита впливають геометричні розміри, маса, структура частинок, їх амплітуда та частота коливання, взаємодія частинок між собою. Продуктивність процесу сепарації, звичайно ж, залежить не тільки від конструкції і виробничих параметрів вібраційного сепаратора, але й від характеристик завантаженої сировини: щільності шару, твердості частинок, їх структури, швидкості руху, амплітуди коливання. Тому на сьогод- ні вже проведено велику кількість досліджень та моделювань руху завантаженої на вібрувальне сито сипкої сировини на підставі багатьох гіпотез, зокрема, розгля-

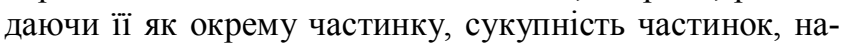
шарування шарів частинок, суцільного тіла та інших. Проте жодна 3 цих гіпотез не описує характер процесу вібраційної сепарації сипкої сировини в повному обсязі, тому здійснення подальших досліджень $є$ і надалі актуальним.

Враховуючи зазначене вище, доцільно виконати моделювання та розрахунок впливу різних параметрів сипкої сировини на її амплітудо-частотні характеристики та відповідно на ефективність процесу сепарації.

Об'єкт дослідження - сепарація шару сипкої сировини в робочому контейнері вібраційного сепаратора.

Предмет дослідження - методи і засоби визначення динамічних процесів, які відбуваються в шарі сипкої сировини під час процесу сепарації.

Мета роботи - визначення взаємовпливу швидкості руху шару сипкої сировини вздовж сита вібраційного сепаратора та його амплітудо-частотних характеристик.

Інформація про авторів:

Ребот Дарія Петрівна, канд. техн. наук, асистент, кафедра проектування та експлуатації машин. Email: dariiarebot@gmail.com; https://orcid.org/0000-0002-3583-0800

Топільницький Володимир Григорович, канд. техн. наук, доцент, кафедра проектування та експлуатації машин. Email: topilnvol@gmail.com; https://orcid.org/0000-0002-5191-326X

цитування за ДСту: Ребот Д. П., Топільницький В. Г. Математичне моделювання взаємовпливу динамічних характеристик сипкої сировини у процесі вібраційної сепарації. Науковий вісник НлТУ України. 2021, т. 31, № 2. С. 88-92.

Citation APA: Rebot, D. P., \& Topilnytskyy, V. H. (2021). Mathematical modeling of the interaction of dynamic characteristics of bulk raw materials in the process of vibration separation. Scientific Bulletin of UNFU, 31(2), 88-92. https://doi.org/10.36930/40310214 
Для досягнення зазначеної мети визначено такі основні завдання дослідження: побудувати математичну модель руху сипкої сировини вздовж сита вібраційного сепаратора; виконати графічне моделювання зміни амплітудо-частотних показників у процесі сепарації.

Наукова новизна отриманих результатів дослідження - вперше побудовано математичну модель 3 використанням законів нелінійної механіки та виконано графічне моделювання взаємозалежності динамічних параметрів сипкої сировини, зокрема іiї швидкості руху та амплітудо-частотних характеристик.

Практична значущість результатів дослідження можна використати під час розроблення та конструювання сепараторів для конкретних типів сипких матеріалів, а також для оптимізації процесів сепарації на вібраційних сепараторах.

Аналіз останніх досліджень та публікацій. Сучасні дослідження показують, що фізико-механічні характеристики сипкої сировини та ії взаємодія з поверхнею сита впливають на ефективність сепарації. Чимало науковців досліджують вплив швидкості завантаження та руху сипкої сировини по ситі сепаратора на показники процесу сепарації. Зокрема, розглянуто залежність продуктивності та якості просіювання від швидкості подачі сировини. Встановлено, що швидкість подачі сипкої сировини повинна зростати із зростанням довжини поверхні сита. В іншому випадку зростання швидкості подачі призведе до забивання та налипання суміші в робочому контейнері та зниження ефективності сепарації як важко-, так і легкопрохідних частинок $[2,4]$. Також способом математичного моделювання з'ясовано, що збільшення потужності подачі сипкої сировини на понад 80 \% призводить до повної втрати ефективності сепарації. Тобто зміна швидкості подачі сировини та їі фізикомеханічні властивості прямо впливають на ефективність просіювання. Також збільшення ємності робочого корпуса вібраційного сепаратора призводить до зменшення ефективності просіювання [7]. На підставі модуля EDEM проведено моделювання поведінки сипкого матеріалу на поверхні сита сепаратора. Зокрема, розглянуто швидкість потоку матеріалу, зміну шару матеріалу вздовж сита, як за сталої, так і змінної амплітуди коливання. Встановлено, що швидкість руху частинок сипкого матеріалу зменшується по довжині його руху ситом [5]. Також зменшення довжини сита, товщини шару сипкого матеріалу, форми матеріалу призводить до налипання, утруднення прохідності частинок та зменшення ефективності сепарації $[1,3]$. Важливими чинниками, які впливають на взаємодію сипкого матеріалу 3 робочим контейнером, $є$ також кути нахилу сита, амплітуда та частота коливання сировини, зокрема зменшення амплітуди та кута нахилу сита призводять до зменшення сили удару сипкого матеріалу та можуть запобігти пошкодженню сита у разі сепарації важких і гострих матеріалів [12].

Значна частина досліджень $[6,9,10,11]$ руху сипких матеріалів на ситі сепаратора показала, що для опису механізму взаємодії між частинками та робочою поверхнею необхідна велика кількість диференціальних рівнянь, які позаяк не дають повної інформації про характер руху сипкого матеріалу загалом. Тому варто розглянути сипкий матеріал на підставі інтегрального підходу, охарактеризувавши шар матеріалу деякими узагаль- неними параметрами та приймаючи його як пружне суцільне тіло. Зокрема, шар сипкого матеріалу розглядають як нашарування плоских пружно-пластичних балок, які пружно взаємодіють між собою та стінками контейнера сепаратора та знаходяться під певним кутом до горизонту. На підставі зазначеної вище моделі пропонують дослідити зв'язок швидкості руху сипкої сировини вздовж сита вібраційного сепаратора $з$ іiї амплітудо-частотними характеристиками.

Матеріали та методи дослідження. Використовуючи CAE систему Mathcad побудовано математичну модель руху шару сипкої сировини на ситі вібраційного сепаратора. Для побудови математичної моделі використано методи нелінійної механіки, зокрема закон Фойгта, методи Крилова та Боголюбова, принцип Остроградського-Гамільтона. На підставі отриманої математичної моделі виконано графічне моделювання взаємовпливу швидкості сипкої сировини та їі амплітудо-частотних характеристик.

\section{Результати дослідження та їх обговорення}

Рівняння шару сипкої сировини, за умови моделювання його плоскою, пружно-пластичною балкою, матиме такий вигляд:

$$
\begin{aligned}
\frac{\partial^{2} u(x, t)}{\partial t^{2}} & +2 V \frac{\partial^{2} u(x, t)}{\partial x \partial t}-\left(\alpha^{2}-V^{2}\right) \frac{\partial^{2} u(x, t)}{\partial x^{2}}= \\
& =\varepsilon \cdot f\left(x, \frac{\partial u(x, t)}{\partial x}, \frac{\partial u(x, t)}{\partial t}\right),
\end{aligned}
$$

де: $\alpha^{2}=E S$ / $\rho$ - функція, яка описує фізико-механічні характеристики шару сипкої сировини; $u(x, t)$ - переміщення вздовж сита перерізу елементарного шару сипкої сировини із координатою $x$ у довільний проміжок часу $t ; v$ - коефіцієнт, який враховує пружні властивості сипкої сировини; $V$ - швидкість руху шару сипкої сировини вздовж сита; $\varepsilon$ - деякий малий параметр, який вказує на відхилення пружних інтегральних властивостей сипкої сировини від лінійного закону; $f$ - функція, яка характеризує нелінійне відхилення пружних властивостей матеріалу сипкої сировини від лінійного закону. Малий параметр $\varepsilon$ вказує на те, що максимальне значення впливу нелінійних та періодичних сил у шарі сипкої сировини є малим порівняно із відновлювальною силою. Доданки рівняння (1) $2 V \frac{\partial^{2} u(x, t)}{\partial x \partial t}$ та $V^{2} \frac{\partial^{2} u(x, t)}{\partial x^{2}}$ враховують рух сипкої сировини вздовж сита.

Як вже було зазначено в попередніх дослідженнях [8], враховуючи, що шар сипкої сировини контактує із стінками робочого контейнера вібраційного сепаратора пружно (рис. 1), крайові умови матимуть такий вигляд.

$$
u(x, t)_{\mid x=0}=u(x, t)_{\mid x=l}=0 .
$$

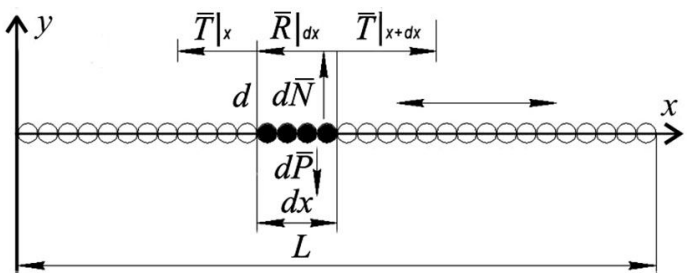

Рис. 1. Схема шару сипкої сировини та сил, які діють на її частинку 
Якщо врахувати, що усереднені пружні властивості сипкої сировини задовольняють близький до лінійного закон пружності, то основою для математичної моделі динаміки сипкої сировини буде саме рівняння (1) 3 крайовими умовами (2).

Швидкість руху сипкої сировини вздовж сита може бути різною і відповідно по-різному впливати на значення амплітудо-частотних показників іiі коливання. Якщо розглядати випадок малої швидкості руху сипкої сировини вздовж сита, то зі застосуванням методу Крилова-Боголюбова отримаємо перше одночастотне наближення у вигляді

$$
\begin{gathered}
\frac{\partial^{2} u_{1}}{\partial \psi^{2}} \omega^{2}+\frac{\partial^{2} u_{1}}{\partial \theta^{2}} \mu^{2}+2 \frac{\partial^{2} u_{1}}{\partial \theta \partial \psi} \mu \omega-\alpha^{2} \frac{\partial^{2} u_{1}}{\partial x^{2}}= \\
=\sin \frac{k \pi}{l} x\left(2 a \omega A_{1}(a) \sin \psi+2 \omega a B_{1}(a) \cos \psi+\left(\frac{k \pi}{l}\right)^{2} .\right. \\
\left.V^{2} a \cos \psi\right)+2\left(\frac{k \pi}{l}\right) V a \omega \cos \frac{k \pi}{l} x \sin \psi+F(a, \psi, \theta, x),
\end{gathered}
$$

де: $\omega, \mu$ - відповідно частота власних коливань сипкої сировини та частота зовнішнього збурення; $\psi$ - фаза одночастотного процесу.

Тоді перше наближення амплітудо-фазової характеристики динамічного процесу сипкої сировини визначають залежностями:

$$
\begin{aligned}
\frac{d a}{d t} & =\varepsilon \frac{1}{P} \frac{1}{4 \omega \pi^{2}} \int_{0}^{l} \int_{0}^{2 \pi} \int_{0}^{2 \pi} F(a, x, \psi, \theta) F(a, x, \psi) \sin \frac{\pi}{l} x \sin \psi d x d \psi d \theta,(4) \\
\frac{d \psi}{d t} & =\omega-\left(\frac{k \pi}{l}\right)^{2} \frac{1}{\omega} V^{2}+\varepsilon \frac{1}{P} \frac{1}{4 \omega \pi^{2} a} \int_{0}^{l} \int_{0}^{2 \pi} F(a, x, \psi) \sin \frac{\pi}{l} x \cos \psi d x d \psi .
\end{aligned}
$$

Саме дослідження розв'язків математичних моделей різного типу динамічних процесів у сипкій сировині з урахуванням всієї сукупності сил, зокрема й періодичних, дає змогу раціонально сконструювати вібросепараційні машини із найбільшою продуктивністю роботи. А отримання у параметризованій формі зручних для інженерних розрахунків аналітичних співвідношень, які описують динамічні процеси в шарі матеріалу та характеризуються сталою швидкістю поздовжнього руху 3 урахуванням всього спектра силових чинників, зокрема й періодичних, є важливою задачею. Варто зауважити, що дія на шар сировини періодичних сил, частоти яких $є$ близькими до частот власних коливань сипкої сировини, точніше кажучи, знаходяться у раціональному співвідношенні із основною частотою всієї їх сукупності, призводить до значного росту амплітуди коливань, а отже, до виникнення у сипкій сировині достатньо великих амплітуд коливань, цим самим покращуючи процес розрихлення сировини та її сепарацію. Тому під час побудови математичної моделі руху шару сировини варто враховувати те, що на динамічний процес в ній впливають не тільки нелінійні сили, а й співвідношення між частотами власних і вимушених коливань. Такий вплив найкраще проявляється в резонансному випадку, коли між частотою зовнішнього періодичного збурення $\mu$ i власною $\omega$ частотою існує взаємозв'язок.

Якщо в задані рівняння додати залежність швидкості руху сипкої сировини від основних її фізико-механічних характеристик. $V_{\kappa p}=\sqrt{\frac{E S}{\rho}}$ (прийнявши при цьому $S=0,00072 \mathrm{M}^{2}$ ), то проведення графічного моделювання покаже, що збільшення умовного модуля пружності сипкої сировини веде до зростання швидкості іiї руху вздовж сита, а зростання густини в 1,5 раза - до зменшення швидкості в два рази.

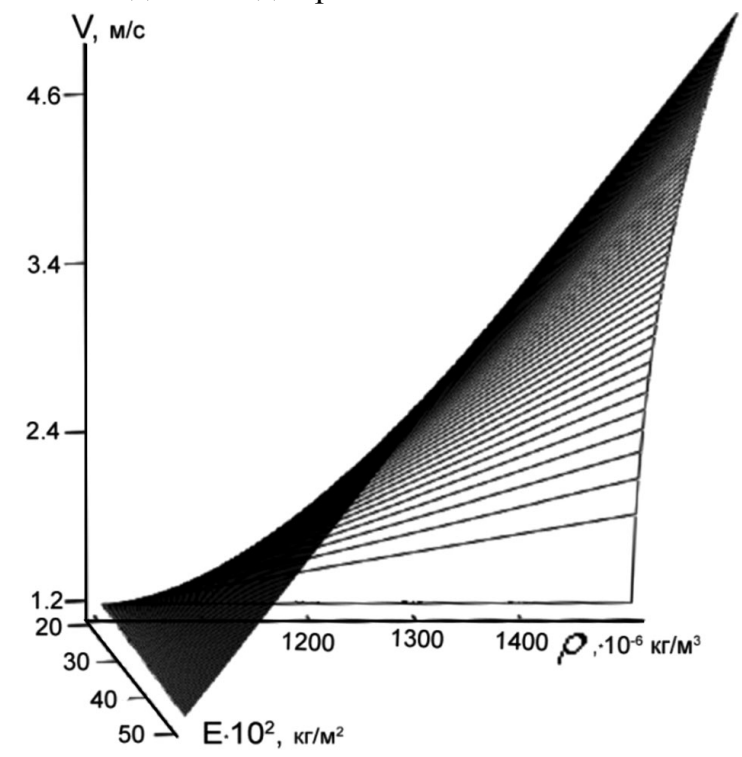

Рис. 2. Зміна швидкості руху сипкої сировини вздовж сита вібросепаратора від зміни ії густини та умовного модуля пружності

За умови, що частота власних коливань сипкої сировини буде наближатись до частоти зовнішнього збурення, довжина сита вібраційного сепаратора $l=1 \mathrm{M}$, площа перерізу шару сипкої сировини $S=0,00072 \mathrm{~m}^{2}$, маса $m=100 \kappa{ }^{2}$, умовний модуль пружності шару $E=100000 \mathrm{H} / \mathrm{m}^{2}$, власна частота коливання шару завантаження $\omega=31,46$ Гц, то амплітуда та фаза коливань сипкої сировини визначатимуть такими залежностями:

$$
\begin{aligned}
\frac{d a}{d t} & =-\frac{\varepsilon H}{\pi(\omega+\mu)} \cos \psi, \\
\frac{d \psi}{d t} & =\omega-\mu-\varepsilon\left(\frac{3}{16} \frac{E \pi^{3} a^{2}}{\omega l}+\frac{V^{2} \pi^{2}}{4 \omega l}\right)+\frac{h}{\pi(\omega+\mu) a} \sin \psi,
\end{aligned}
$$

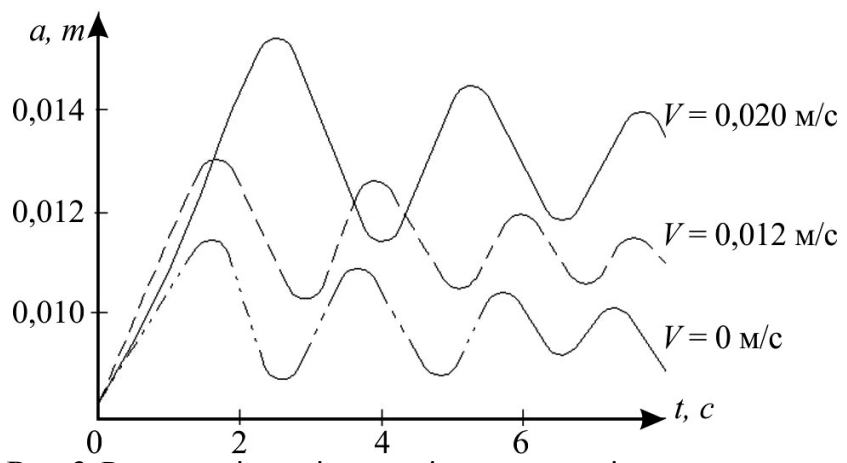

Рис. 3. Резонансні амплітуди, які виникають під час коливання сипкої сировини для різних швидкостей іiї руху

Як можна побачити з графічної залежності, зображеної на рис. 3, незначне зростання швидкості поздовжнього руху сипкої сировини призводить до зростання амплітуди коливання завантаженого шару. Тобто для малих значень швидкостей поздовжнього руху сипкого середовища резонансна частота $є$ меншою, а амплітуда коливань більшою.

Якщо розглядати випадок більших швидкостей руху сипкої сировини, то резонансні криві визначають диференціальними рівняннями: 


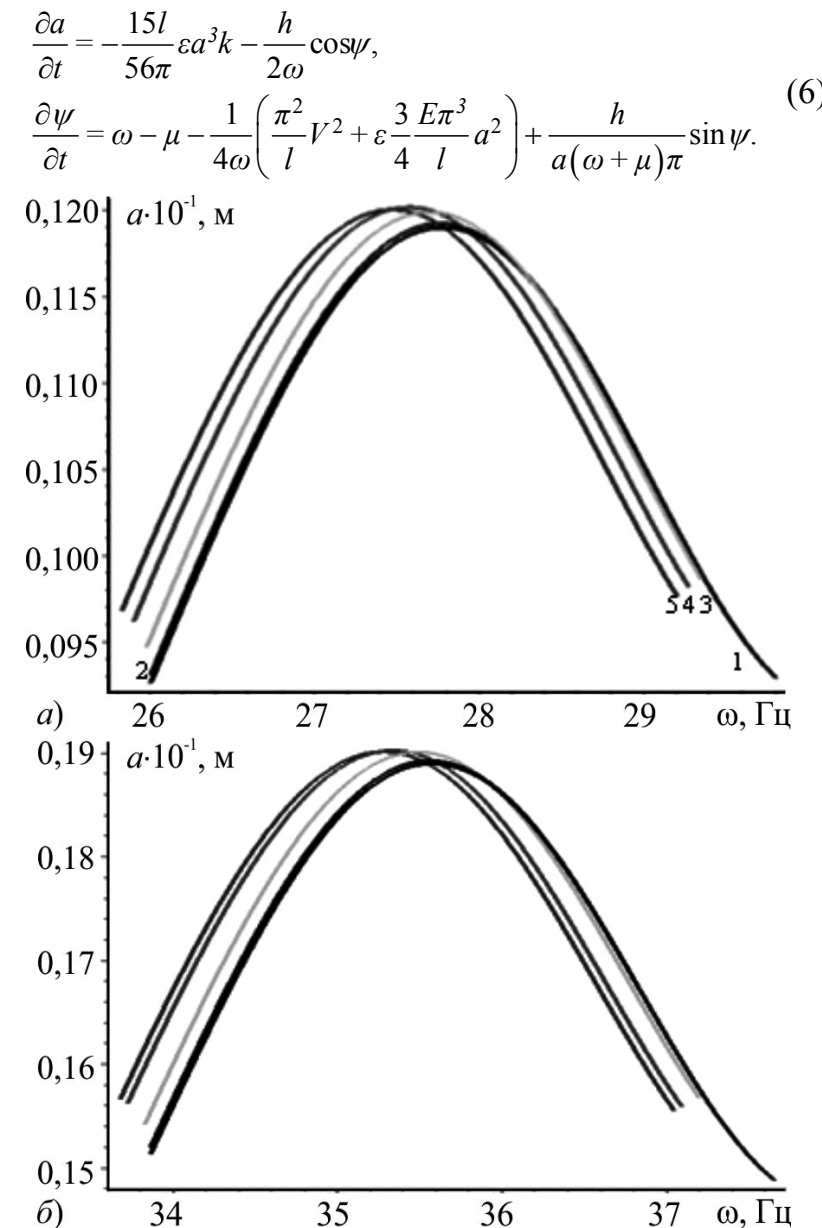

Рис. 4. Залежності зміни амплітуди коливань сипкої сировини від частоти коливань контейнера сепаратора, за різних швидкостей поздовжнього руху шару завантаження

Для випадку $a$ ) взято такі дані $V: 1-V=8 \mathrm{~m} / \mathrm{c} ; 2-$ $V=5 \mathrm{M} / \mathrm{c} ; 3-V=3 \mathrm{M} / \mathrm{c} ; 4-V=2 \mathrm{M} / \mathrm{c} ; 5-V=1 \mathrm{M} / \mathrm{c} ;$ $\alpha=30 ; \varepsilon=0,01 ; h=0,001 ; k=1$; для випадку б): $V: 1-$ $V=8 \mathrm{M} / \mathrm{c} ; 2-V=5 \mathrm{M} / \mathrm{c} ; 3-V=3 \mathrm{M} / \mathrm{c} ; 4-V=2 \mathrm{M} / \mathrm{c} ; 5-$ $V=1 \mathrm{M} / \mathrm{c} ; \alpha=40 ; \varepsilon=0,01 ; h=0,001 ; k=1 ; \beta) 1-V=1,6$ $\mathrm{M} / \mathrm{c} ; 2-V=1,4 \mathrm{M} / \mathrm{c} ; 3-V=1,2 \mathrm{M} / \mathrm{c} ; 4-V=1 \mathrm{M} / \mathrm{c} ; 5-$ $V=0 \mathrm{M} / \mathrm{c} ; \alpha=30 ; \varepsilon=0,001 ; h=0,0005 ; k=1$.

Отримані розрахункові залежності та побудовані на їх основі графічні залежності показують, що зменшення відносної швидкості руху сипкої сировини вздовж сита вібраційного сепаратора призводить до зростання резонансної амплітуди коливання та спадання частоти коливання. Для великих значень швидкості руху сипкої сировини резонансна амплітуда і частота є достатньо малими порівняно з резонансними коливаннями за малої швидкості руху вздовж сита. Отже, можна зробити висновок, що процес сепарації за великих швидкостей руху сипкої сировини, навіть за ії резонансних коливань, є дуже повільним. За більших значень частоти власних коливань сипкої сировини вплив зовнішнього періодичного збурення проявляється меншою мірою, ніж за менших iï значень. Стала складова швидкості сипкої сировини призводить до збільшення її частоти власних коливань, а це також погіршує продуктивність процесу сепарації. Провідну роль у резонансних коливаннях відіграють фізико-механічні властивості сипкої сировини (порівняно з величиною початкової амплітуди та амплітуди періодичного збурення).

\section{Висновки}

Побудована математична модель та отримано графічні залежності, які дають змогу в подальшому коригувати амплітудо-частотні характеристики сипкої сировини залежно від фізико-механічних властивостей матеріалу завантаження, кута нахилу сита сепаратора до горизонту та швидкості завантаження сировини. Ці розрахунки дають змогу регулювати динамічні параметри процесу сепарації та коригувати конструкцію сепараторів для оптимізації процесу сепарації.

Встановлено, що сталі складові швидкостей впливають на збільшення власної частоти коливань сипкої сировини, що відповідно погіршує ефективність проходження частинок крізь сито сепаратора. Невеликі швидкості руху шару сипкої сировини призводять до зростання амплітуди коливання та зменшення частоти коливання, що сприяє підвищенню прохідності частинок сировини та збільшенню продуктивності процесу сепарації.

Отримані дослідження дають змогу покращити ефективність процесу сепарування, регулювати процеси, які відбуваються у сипкій сировині та підвищити швидкість ії проходження крізь отвори сита. Побудована математична модель може слугувати основою для подальших досліджень зміни фізико-механічних характеристик сипкої сировини на ії динамічні показники в процесі вібраційної сепарації.

\section{References}

1. Chi Yu, Xinwen Wang, Kunfeng Pang, et. al. (2020). Dynamic characteristics of a vibrating flip flow screen and analysis for screening $3 \mathrm{~mm}$ iron ore. Shock and Vibration, 31(6). https://doi.org/10.1155/2020/1031659

2. Evtukov, S. A., Sizikov, \& V. S., Rajczyk, J. (2016). Modelirovanie processa peremescheniia sypuchey sredy po sytu vibroydarnogo grohota. Zeszyty Naukowe Politechniki Częstochowskiej Budownictwo, 22, 86-94. https://doi.org/10.17512/znb.2016.1.07

3. Fernandeza, J. W., Clearya, P. W., Sinnotta, M. D., \& Morrison, R. D. (2011). Using SPH one-way coupled to DEM to model wet industrial banana screens. Minerals Engineering, 24(8), 741-753. https://doi.org/10.1016/j.mineng.2011.01.004

4. Honghai, Liu, Jie Jia, Nieyangzi, Liu, et. al. (2018). Effect of material feed rate on sieving performance of vibrating screen for batch mixing equipment. Powder Technology, 338, 898-904. https://doi.org/10.1016/i.powtec.2018.07.046

5. Junpeng, Qiao, et. al. (2018). Research on screening mechanism and parameters optimization of equal thickness screen with variable amplitude based on DEM simulation. Powder Technology, 331(15), 296-309. https://doi.org/10.1016/j.powtec.2018.03.031

6. Lapshyn, V. L., Rydyh, A. V., \& Glyhov, A. V. (2015). Matematicheskoe modelirovanie procesa vibracionnogo dvigeniia chastici materiala po rabochemy organy separatora. Scientific Bulletin of Irkutsk State Technical University, 3(98), 49-55.

7. Nicolus, Rotich, Ritva, Tuunila, et. al. (2017). Dynamic and perturbative system analysis of granular material in a vibrating screen. Advanced Powder Technology, 28(12), 3257-3264. https://doi.org/10.1016/j.apt.2017.09.031

8. Rebot, D. P., Topilnytskyy, V. G. (2018). Matematychna model vyznachennia zminy amplitydu ta chastoty kolyvannia sypkogo materialy v procesi vibroseparacii. Scientific Bulletin of UNFU, 28(2), 164-166. https://doi.org/10.15421/40280231

9. Stotsko, Z. A., Rebot, D. P. (2014). Vplyv dynamiky ryhy sypkogo seredovyshcha na prodyktyvnist vibraciynych separatoriv. Naykovyi ghyrnal Technologichni Kompleksy, 1(9), 150-153.

10. Wang, L., Ding, Z., et al. (2017). Kinematics and dynamics of a particle on a non-simple harmonic vibrating screen. Particuology, 32, 167-177. https://doi.org/10.1016/j.partic.2016.11.002

11. Zheng Wang, Nicholas J. Miles, et. al. (2016). Recycling oriented vertical vibratory separation of copper and polypropylene particles. Powder Technology, 301, 694-700. https://doi.org/10.1016/j.powtec.2016.06.003 
12. Zhenqian, Wang. (2019). Research on impact characteristics of screening coals on vibrating screen based on discrete-finite ele- ment method. Energy Sources, 42(16), 1963-1976. https://doi.org/10.1080/15567036.2019.1604905

D. P. Rebot, V. H. Topilnytskyy

Lviv Polytechnic National University, Lviv, Ukraine

\section{MATHEMATICAL MODELING OF THE INTERACTION OF DYNAMIC CHARACTERISTICS OF BULK RAW MATERIALS IN THE PROCESS OF VIBRATION SEPARATION}

The separation process largely depends on the dynamic characteristics of the layer of bulk raw materials. In particular, it is known that the amplitude, oscillation frequency of the raw material layer, its speed along the sieve affect the speed of passage of the medium particles through the sieve holes and, accordingly, the efficiency of the separation process. A review of the literature confirmed that the question of the relationship of the dynamic parameters of bulk raw materials in the process of its vibrational separation is relevant today. To determine the interaction of these parameters, a mathematical model of the movement of the layer of bulk raw material along the sieve of the vibrating separator is built. Methods of nonlinear mechanics were used to build a mathematical model; graphical dependences were built in the CAD system Mathcad. The layer of bulk raw materials during the study was modeled as a layer of flat elastic-plastic beams in contact with each other and with the walls of the working container of the vibrating separator elastic, rigid or hinged. Graphical dependences of the velocity influence of the bulk raw material layer on the amplitude and frequency of its oscillations are obtained. The obtained mathematical model and graphical dependences show that a significant increase in the velocity of bulk raw material along the sieve leads to a decrease in the amplitude and a slight increase in the frequency of oscillations of the layer of loaded raw material. Similarly, the constant components of the velocities affect the increase in the natural frequency of oscillations of the bulk raw material, which in turn impairs the efficiency of the passage of particles through the sieve of the separator. Low velocities of the bulk raw material layer lead to an increase in the oscillation amplitude and a decrease in the oscillation frequency, which in turn helps to increase the permeability of the raw material particles and increase the productivity of the separation process. The obtained studies make it possible to improve the efficiency of the separation process, to regulate the processes that take place in the bulk raw material and to increase the speed of its passage through the sieve holes. The constructed mathematical model can serve as a basis for further research of change of physical and mechanical characteristics of loose raw materials on its dynamic indicators in the vibration separation process.

Keywords: dynamic characteristics; amplitude; frequency; bulk raw materials; mathematical model. 